\title{
Deducing false propositions from true ideas: Nieuwentijt on mathematical reasoning
}

\author{
Sylvia Pauw ${ }^{1,2}$
}

Received: 22 November 2017 / Accepted: 17 September 2018 / Published online: 29 September 2018 (c) The Author(s) 2018

\begin{abstract}
This paper argues that, for Bernard Nieuwentijt (1654-1718), mathematical reasoning on the basis of ideas is not the same as logical reasoning on the basis of propositions. Noting that the two types of reasoning differ helps make sense of a peculiar-sounding claim Nieuwentijt makes, namely that it is possible to mathematically deduce false propositions from true abstracted ideas. I propose to interpret Nieuwentijt's abstracted ideas as incomplete mental copies of existing objects. I argue that, according to Nieuwentijt, a proposition is mathematically deducible from an abstracted idea if it can be demonstrated that that proposition makes a true claim about the object that idea forms. This allows me to explain why Nieuwentijt deems it possible to deduce false propositions from true ideas. It also implies that logic and mathematics are not as closely related for Nieuwentijt as has been suggested in the existing secondary literature.
\end{abstract}

Keywords Nieuwentijt · Mathematical deduction · Logical deduction · Abstraction

\section{Introduction}

In his 1720 work on the nature of pure and mixed mathematics, Grounds of Certainty ${ }^{1}$ (Gronden van zekerheid), the Dutch philosopher Bernard Nieuwentijt suggests that he regards logic and mathematics as intimately related. In a chapter that is concerned with logic, Nieuwentijt claims to show "[...] that true Logicians [...] only differ from the true Mathematicians in the outer Ways [uiterlyke Omstandigheden] of expressing

$\overline{1}$ Translation adopted from Ducheyne (2007). Throughout this paper, I use GC as abbreviation for Grounds of Certainty (i.e. Nieuwentijt 1720), and use it to give references to page numbers of this work.

$凶$ Sylvia Pauw

sylvia.pauw@gmail.com

1 Department of Political Science, University of Amsterdam, PO box 15578, 1001 NB Amsterdam, The Netherlands

2 Department of Philosophy and Moral Sciences, Ghent University, Blandijnberg 2, 9000 Ghent, Belgium 
their proofs, yet not at all in the force of Arguments"2 (GC, p. 218). He also claims to show that "[...] the true mathematicians agree with the logicians, and do not fundamentally differ [in den gront niet verschillen]"3 (GC, p. 204). Nieuwentijt's remarks have led Ducheyne (2017b, p. 287n.) to claim that Nieuwentijt regards logic as a part of pure mathematics. Petry suggests that mixed mathematics forms, to a certain extent, a "branch of logic" (1979, p. 6) for Nieuwentijt. ${ }^{4}$ Beth (1954, pp. 451-452) even compares Nieuwentijt's position to logicism.

In this paper, I argue that Nieuwentijt does not identify mathematical reasoning with logical reasoning, and that the existing accounts of his views on the relationship between logic and mathematics cannot be correct. In his analysis of the nature of mixed mathematics, Nieuwentijt claims that it is possible to mathematically deduce false propositions from true abstracted ideas. ${ }^{5}$ An abstracted idea of an object is an idea that represents some, but not all of that object's properties. ${ }^{6}$ If, in Nieuwentijt's eyes, mathematically deducing propositions from true abstracted ideas would be the same as logically deducing propositions from true propositions, then his claim would be a very odd one. As Nieuwentijt himself emphasizes, it is not his view that we can logically deduce false propositions from true premises. In fact, the point of Nieuwentijt's discussion of logic in Grounds of Certainty is to stress this. There is no disagreement between the mathematicians and the logicians, Nieuwentijt explains, because the mathematicians accept that a proposition that is logically deduced from true premises must be true as well (GC, pp. 214-216). This does not mean that mathematical reasoning is the same as logical reasoning according to Nieuwentijt, on the contrary. Nieuwentijt characterizes mathematical reasoning as the examination and comparison of ideas. Both in pure and in mixed mathematics we can discover truths by mathematically deducing propositions from ideas. As I show in this paper, deducing propositions from ideas is something different from logically deducing propositions from other propositions for Nieuwentijt. According to Nieuwentijt, ideas allow us to deduce truths that cannot be deduced logically.

This paper is structured as follows: Sect. 2 shows that Nieuwentijt's claim that it possible to deduce false propositions from true abstracted ideas would be problematic if he identified mathematical deduction on the basis of ideas with logical deduction on the basis of propositions. Section 3 considers what it means to deduce a proposition from ideas by analyzing Nieuwentijt's views on pure mathematics. We see that, according to Nieuwentijt, we deduce a proposition from ideas by showing that that proposition makes a true claim about these ideas. In Sect. 4, I analyze Nieuwentijt's notion of

\footnotetext{
2 "[...] dat ware Logici [...] alleen in de uiterlyke Omstandigheden van haar bewysen uit te drukken, dog geensints in de kragt der Betogingen, van de ware Mathematici verschillen".

3 "[...] de ware mathematici met de logici overeenkomen, en in den gront niet verschillen".

4 Petry uses the term 'applied mathematics' instead of 'mixed mathematics'.

5 I translate Nieuwentijt's term 'voorstel' as 'proposition'. Note that Nieuwentijt's use of the term 'voorstel' diverges somewhat from our ordinary use of 'proposition'. As becomes clear in the course of this paper, Nieuwentijt believes that one and the same proposition can have different truth values, because it can be regarded as speaking of an existing object, but also as speaking of an idea of an existing object.

6 Nieuwentijt's views on abstracted ideas are discussed by Beth (1954, pp. 449-451) and Ducheyne (2007, pp. 704-710; 2017b, pp. 288-290). I criticize aspects of Ducheyne's (2017b) account in section 2 of this paper.
} 
an abstracted idea. I show that, given a specific interpretation of this notion, and Nieuwentijt's conception of mathematical reasoning, it makes sense for him to claim that it is possible to deduce false propositions from true abstracted ideas. In Sect. 5, I explain how mathematical reasoning on the basis of ideas differs from logical reasoning in Nieuwentijt's thinking. We see that whether or not a proposition is mathematically deducible from ideas is determined by these ideas, according to Nieuwentijt. Whether a proposition can be logically deduced from other propositions, by contrast, does not rely on ideas. We see that Nieuwentijt is implicitly committed to a view that Macbeth (2017) ascribes to Descartes, namely the view that mathematical truths have a different type of necessity than logical truths.

\section{The problem}

As Ducheyne (2007, p. 704) has pointed out, Nieuwentijt uses his notion of an abstracted idea to provide an early account of the use of idealization and abstraction in science. ${ }^{7}$ Nieuwentijt observes that scientists often derive conclusions by neglecting specific aspects of the phenomena they study. Such conclusions are certainly true under specific idealized circumstances, Nieuwentijt points out, but they may not be true under normal circumstances (cf. Ducheyne 2007, pp. 704-707; 2017b, pp. 288-289). Put in our terms, Nieuwentijt notes that many scientific claims are true ceteris paribus only (cf. Ducheyne 2017b, pp. 288-289). ${ }^{8}$ Nieuwentijt makes this point by arguing that scientists, or mixed mathematicians, tend to reason on the basis of abstracted ideas of the existing objects they study. For Nieuwentijt, an idea of an object is adequate if it represents or "shows" (vertoont) all of that object's properties (GC, p. 44). An abstracted or "subtracted"9 (afgetrokken) idea is an idea that represents some, but not all of its object's properties $(G C$, p. 45$) .{ }^{10}$ Scientists or mixed mathematicians who neglect the influence of air resistance on some phenomenon, for instance, reason on the basis of abstracted ideas, in Nieuwentijt's eyes (e.g. GC, pp. 64-65; cf. Ducheyne 2007, pp. 704-707; 2017b, p. 289). According to Nieuwentijt, a proposition that is deduced from an abstracted idea of an existing object would certainly be true if that existing object had no properties other than those the abstracted idea represents $(G C$, p. 63). However, because the object typically does have other properties, the deduced propositions may be false. Nieuwentijt claims that even if the abstracted ideas on the basis of which mixed mathematicians reason are true, propositions that are deduced from them may be false (e.g. $G C$, p. 74). If Nieuwentijt equated the mathematical

\footnotetext{
7 See also Ducheyne (2007, 2017b, esp. pp. 286-295) for discussions of Nieuwentijt's views on abstraction and of the role of abstraction in Nieuwentijt's wider philosophical project.

8 I would like to thank an anonymous reviewer who proposed to clarify Nieuwentijt's position in these terms. See e.g. Cartwright, who characterizes ceteris paribus generalizations as "generalizations that hold under special conditions, usually ideal conditions" (Cartwright 1983, p. 45). Note that I do not wish to suggest that it is Nieuwentijt's view that all scientific knowledge consists of lawlike statements.

9 Translation adopted from Ducheyne (2007). Thanks to an anonymous reviewer for suggesting to refer to these ideas as 'abstracted' ideas. Cf. also Ducheyne (2017a, b).

10 See also Ducheyne (2007, pp. 704-705; 2017a, section 2; b, p. 228) for discussion of Nieuwentijt's notion of an abstracted idea.
} 
deduction from ideas with logical deduction from propositions, this claim would be problematic. We see this when we consider what it means for propositions to be true, in Nieuwentijt's eyes, and what this means for abstracted ideas.

Nieuwentijt's discussion of abstraction forms part of his analysis of the nature of mixed or "factual" (sakelyke) ${ }^{11}$ mathematics. According to Nieuwentijt, mixed mathematics differs from pure or "imaginary" (denkbeeldige) ${ }^{12}$ mathematics, because it aims to provide knowledge of existing things (wesentlyke saken). ${ }^{13}$ To obtain such knowledge, it must base its results not just on reason, but also on empirical data or "experiences" (ondervindingen), Nieuwentijt argues. In pure mathematics we obtain knowledge independently from sensory experience, by reasoning on the basis of so-called "bare ideas"14 (blote denkbeelden), according to Nieuwentijt. ${ }^{15}$ Pure mathematicians reason on the basis of ideas of mathematical objects such as triangles and circles, without verifying whether these ideas correspond to any existing entities. ${ }^{16}$ For this reason, these ideas are nothing but ideas or "bare" ideas, in Nieuwentijt's eyes. Pure mathematics as such cannot discover truths about existing objects, Nieuwentijt argues. It can only discover truths about bare ideas themselves (GC, pp. 21-22). ${ }^{17}$ In the next section we consider what exactly bare ideas are, and what it means for propositions to be true of such ideas.

Unlike pure mathematicians, mixed mathematicians seek to form ideas that correspond to existing things, so-called "factual ideas" (sakelyke denkbeelden, e.g. GC, p. 40), Nieuwentijt argues. They do so by basing their ideas on experimental data or "grounding experiences" (grond-ondervindingen) of existing objects (GC, p. 40; cf. Beth 1954, p. 449; Ducheyne 2017a, section 2; b, p. 287). By reasoning on the basis of these ideas, mixed mathematicians deduce new claims about the objects they study (GC, pp. 48-51; cf. Beth 1954, pp. 449-451). Only if these claims are confirmed by further empirical data or "test experiences" (proef-ondervindingen) can we accept them as true, Nieuwentijt argues. More precisely, only then can we accept them as what Nieuwentijt calls "factually true" (sakelyk waar, e.g. GC, pp. 214, 131) (see GC, pp. 80-81; cf. Beth 1954, pp. 450-451; Ducheyne 2007, pp. 705-706).

Nieuwentijt distinguishes two ways in which a proposition (voorstel) that makes a claim about existing objects can be true (cf. Ducheyne 2007, pp. 705-706). Proposi-

\footnotetext{
11 Translation adopted from Ducheyne (2007).

12 Translation adopted from Beth (1954), Petry (1979) and Ducheyne (2007, 2017a, b).

13 By "existing things" (wesentlyke saken) Nieuwentijt means entities that exist at some point in time, not only presently exiting entities ( $G C$, p. 28$)$.

14 I thank Jonathan Shaheen for suggesting this translation.

15 See also Beth (1954, pp. 448, 451-452), Ducheyne (2007, pp. 702-704; 2017a, section 2; b, pp. 286-287), Vermij (1991, p. 84) and Petry (1979, p. 5) for discussions of Nieuwentijt's views on pure mathematics. Vermij (1989, esp. pp. 82-83) and Ducheyne (2017b, pp. 275-279; 287) also point to some interesting developments in Nieuwentijt's views on the topic.

16 Nieuwentijt himself is agnostic as to whether such things as mathematical points or mathematical lines could exist (GC, pp. 5-6). Other mathematical entities, such as quantities with more than three dimensions, certainly cannot exist, Nieuwentijt argues (GC, pp. 7-8; cf. Beth 1954, p. 448).

17 Because some bare ideas may correspond to existing objects, pure mathematics can indirectly teach us things about existing objects, according to Nieuwentijt (cf. GC, p. 25). However, whether ideas correspond to existing entities can only be established in mixed mathematics $(G C, \mathrm{p} .26)$. Thanks to an anonymous reviewer for raising questions regarding this issue.
} 
tions that we would normally call true are "factually true" or, as Nieuwentijt also puts it, true "in" (in, e.g. GC, p. 63) an existing thing. A proposition is factually true if it makes a claim about existing objects, and the existing objects it speaks of have the properties that the proposition ascribes to them $(G C$, pp. 51-52). Propositions can also be true "with respect to" (in opsigt van, e.g. GC, pp. 63, 65) or "in" (in, e.g. pp. 65, 66, $71,74)$ abstracted ideas of existing objects. In Sect. 4, we consider what it means for propositions to be true with respect to abstracted ideas. For now, the important point is that it is Nieuwentijt's view that propositions that are mathematically deduced from abstracted ideas are certainly true with respect to these ideas. However, they may not be factually true, or true "in" the existing objects represented by these ideas, he claims (e.g. GC, pp. 63-65; 66-67; 74-75; cf. Beth 1954, p. 450; Ducheyne 2007, p. 706). The propositions that mixed mathematicians deduce from ideas of existing objects need to be confirmed by sensory data, according to Nieuwentijt, because these ideas are almost always abstracted.

Nieuwentijt not only distinguishes between two ways in which propositions can be true. In addition, he suggests that there are two types of entities that can have truth values, namely propositions and ideas. An idea that represents an existing object or a property of an existing object is true, Nieuwentijt states, if "it shows us either the Thing, or a Property that is in the thing, Truly" "18 (GC, p. 44; cf. Ducheyne 2007, pp. 704-705). Ideas are false if they "show something to us, that Truly is not in the Thing"19 (GC, p. 44). Abstracted ideas form incomplete representations of existing objects, but they can nevertheless be true of these objects according to Nieuwentijt, or at least true in some sense.

Although Nieuwentijt ascribes truth values to abstracted ideas, he does not appear to assign a propositional character to them. Although this is not how Nieuwentijt expresses his point himself, it seems that it is not so much an idea that can be true or false in his eyes, but rather the implicit judgment we make in assuming that an existing object or its properties conform to an idea. ${ }^{20}$ Nieuwentijt only specifies what it means to be true and false for the "factual" ideas that mixed mathematicians form of existing objects $(G C$, p. 44). The bare ideas on the basis of which pure mathematicians reason appear to have no truth value. ${ }^{21}$ Presumably, an idea of a property of existing objects, such as that of two-hundred-meters-high has, as such, no truth value either. However, by assuming that this idea corresponds to the height of, for instance, a specific existing tower, we implicitly form the judgment that that tower is two-hundred meters high. I take it to be Nieuwentijt's view that the idea of two-hundred-meters-high forms a true abstracted idea of the existing tower precisely if this judgment is true.

One might expect that what Nieuwentijt describes as reasoning on the basis of true abstracted ideas consists in reasoning on the basis of the true implicit judgments that arise by assuming that these ideas correspond to features of existing objects. However,

\footnotetext{
18 "als het aan ons of de Saak, of een Eigenschap die in de Saak is, Waarlyk vertoont".

19 "iets aan ons vertonen, dat Waarlyk in de saak niet is".

20 This is roughly Descartes's position in the Third Meditation (see AT VII, p. 37; CSM II, p. 26). I give references to Descartes to volume and page number of the collected works edited by Adam and Tannery (i.e. Descartes 1964-1976), abbreviated as AT, and to volume and page number of the English translation by Cottingham, Stoothoff and Murdoch (i.e. Descartes 1984), abbreviated as CSM.

21 As we see in the upcoming section, mathematical propositions do have a truth value.
} 
if that were so, then Nieuwentijt's claim that it is possible to mathematically deduce false propositions from true abstracted ideas would not make sense. As noted at the beginning of this section, the propositions that Nieuwentijt takes to be deducible from true abstracted ideas, but possibly factually false, are propositions that are true ceteris paribus only. Such propositions cannot be deduced from the implicit judgments that arise by assuming that these abstracted ideas correspond to features of existing objects. If, given the truth of these judgments, a proposition is true ceteris paribus only, then this proposition does not follow from these judgments. Consider, for instance, one of the toy-examples that Nieuwentijt uses to illustrate his claim. Suppose that a person P can lift a bar A that weighs thirty pounds, and that another bar B weighs only ten pounds. According to Nieuwentijt, the proposition $P$ can lift bar $B$ can be deduced from the true abstracted ideas of person P's strength, and those of bar A's and bar B's weight. This proposition is certainly true with respect to these abstracted ideas, Nieuwentijt claims, but because bar B may for instance be burning hot, the proposition may be factually false ( $G C$, p. 71). Nieuwentijt's very example shows that the proposition $P$ can lift bar $B$ cannot be deduced from the propositions $P$ has the strength to lift thirty pounds and bar $B$ weighs ten pounds: it shows that the truth of these propositions does not guarantee the truth of the conclusion.

When we consider an example in which the phenomenon that Nieuwentijt is actually interested in occurs, the same issue arises. ${ }^{22}$ Suppose that a feather falls from a hundred-meter-high tower, and that the gravitational acceleration on earth is exactly $9.8 \mathrm{~m} / \mathrm{s}^{2}$. Nieuwentijt would say that the proposition the feather reaches the ground in $4.52 \mathrm{~s}$ can be deduced from the abstracted ideas of the feather's distance to the earth and the earth's gravitation, even though it is probably false of the real feather. Again, the example itself shows that the proposition the feather reaches the ground in $4.52 \mathrm{~s}$ cannot be deduced from the propositions the gravitational acceleration on earth is exactly $9.8 \mathrm{~m} / \mathrm{s}^{2}$ and the feather falls from a hundred-meter-high tower.

One might think that the issue can be resolved by taking it to be Nieuwentijt's view that true abstracted ideas themselves are true ceteris paribus only. ${ }^{23}$ This is how Ducheyne (2017b, pp. 289-290) understands Nieuwentijt's position. If one reads Nieuwentijt in this way, one can argue, for instance, that the conclusion of our featherexample is deduced from the proposition objects falling near the earth's surface are accelerated with exactly $9.8 \mathrm{~m} / \mathrm{s}^{2}$. This proposition is true ceteris paribus only. Combined with the proposition the feather falls from a hundred-meter-high tower, it allows us to deduce the conclusion the feather reaches the ground in $4.52 \mathrm{~s}$. This solution seems attractive, but it actually amounts to an uncharitable reading of Nieuwentijt's project. Nieuwentijt introduces his notion of an abstracted idea, and his distinction between factual truth and truth with respect to abstracted ideas, to account for what we call the ceteris paribus character of scientific claims. If true abstracted ideas would themselves be true ceteris paribus only, in Nieuwentijt's eyes, then this would deprive these ideas of any explanatory value. Nieuwentijt's point would be that scientific

\footnotetext{
22 Nieuwentijt gives several examples of scientists who admit that their claims are false, or only true if we abstract from certain features of the studied phenomena (e.g. $G C$, pp. 56-57, 64-70). Unfortunately, Nieuwentijt does not tell us which abstracted ideas he takes the scientists in his examples to reason from. For this reason, I do not discuss one of his own examples.

23 I thank an anonymous reviewer for raising this objection.
} 
claims are true ceteris paribus, because they are deduced from ceteris paribus truths. We should not interpret Nieuwentijt in this way, unless we have good reasons for doing so. In fact, there is a good reason to deny that this is Nieuwentijt's view. Nieuwentijt expresses that a proposition is true ceteris paribus by stating that it is true with respect to abstracted ideas, but possibly factually false. For propositions, Nieuwentijt distinguishes between factual truth and truth with respect to abstracted ideas, but he makes no such distinction for abstracted ideas themselves. Abstracted ideas are simply true or false, it seems.

As true abstracted ideas are simply true, and not just true ceteris paribus, we have no way to make sense of Nieuwentijt's claim that it is possible to deduce false propositions from true abstracted ideas if we assume that deducing propositions from true abstracted ideas consists in deducing propositions from true propositions or judgments. As we see in the upcoming sections, deducing propositions from ideas is indeed something different.

\section{Deducing propositions in pure mathematics}

To understand what it means, in mixed mathematics, to mathematically deduce a proposition from abstracted ideas according to Nieuwentijt, we should first consider what it means, in pure mathematics, to mathematically deduce propositions from bare ideas. Nieuwentijt characterizes reasoning in pure mathematics as the examination and comparison of such ideas:

[W] hat do they [i.e. mathematicians] say reasoning is other, but the examination [beschouwen] of Ideas, both [soo] separately in their properties, and [als] in comparison [vergelykinge] with one another? And thus noting, what one experiences [ondervint] every time [telkens] from his Examination of these Ideas? ${ }^{24}$ (GC, p. 18)

To understand Nieuwentijt's characterization, we need to clarify what bare ideas are. To do this, and to get a better understanding of Nieuwentijt's notion of an abstracted idea later on, we take a look at Descartes's distinction between formal and objective reality, and his use of the term 'idea'. In the Meditations, Descartes distinguishes between two types of being or reality: formal and objective reality. Entities that really exist have formal reality. Objective reality forms a lower type of reality that pertains to entities that have reality in our minds as the intentional objects of our ideas (Chappell 1986, pp. 186-188; 1997, p. 120; Nolan 1997, pp. 174-176; Ayers 2000, p. 1067). ${ }^{25}$ An entity that has objective being in our minds may or may not have what Chappell (1986, p. 188) calls a formally existing "counterpart" (cf. Chappell 1997, p. 120; Nolan 1997, p. 175). The intentional object of our idea of a hippogriff, for instance, has objective reality, but as hippogriffs do not exist, it has no formally existing counterpart (cf.

\footnotetext{
24 "[W]at seggen sy dat het redeneren anders is, als het beschouwen der Denkbeelden, soo afsonderlyk in hare eigenschappen, als in vergelykinge met malkander? En dus op te letten, wat men telkens uit dese syne Beschouwingen deser Denkbeelden ondervint?".

25 That Descartes regards objective reality as a lower form of reality becomes clear from AT VII, pp. 102-103; CSM II, p. 75. See Nolan (1997, p. 176), cf. Chappell (1986, p. 187).
} 
Chappell 1986, p. 188). The intentional object of an idea of the sun, on the other hand, has objective being and does have a formally existing counterpart: the real sun (Chappell 1986, pp. 187-188). ${ }^{26}$

Now Descartes regards the intentional object of an idea, i.e. the entity that has objective reality, and the idea itself as one and the same thing (Nolan 1997, pp. 175-176; Chappell 1986, pp. 186-188; Ayers 2000, pp. 1067-1068). As Descartes says in the First Replies:

[T] he idea of the sun is the sun itself existing in the intellect - not of course formally existing, as it does in the heavens, but objectively existing, i.e. in the way in which objects normally are in the intellect (AT VII, 102; CSM II, 75). ${ }^{27}$

In other words: ideas themselves are the entities that have objective being according to Descartes. Our idea of the sun is the objectively existing sun we represent in our minds. More precisely, what Descartes calls ideas taken "objectively" (AT VII, 8; CSM II, 7) are such objective entities (Chappell 1986, pp. 186-188; 1997, p. 120; Nolan 1997, pp. 175-176; Ayers 2000, pp. 1066-1068; cf. Patterson 2008, p. 218). In the Preface to the Meditations, Descartes distinguishes between what he calls an idea taken "materially", which forms an "operation of the intellect" (AT VII, 8; CSM II, 7), and the idea taken "objectively", which is the object that is represented by the idea taken materially (ibid.). The intentional object of the idea taken materially is the idea taken objectively, and this idea is an entity with objective being (Chappell 1986, pp. $184-188$; 1997, p. 120; Patterson 2008, p. 218; Ayers 2000, pp. 1067-1068). ${ }^{28}$ What Descartes describes as "the sun itself existing in the intellect" is the idea of the sun taken objectively (Chappell 1986, pp. 186-188; 1997, p. 120; Ayers 2000, pp. 1067-1068; cf. Nolan 1997, pp. 175-176). ${ }^{29}$

When Nieuwentijt speaks of bare ideas, he uses the term 'idea' in the same way Descartes does when he speaks of ideas taken objectively. ${ }^{30}$ The bare ideas on the basis of which Nieuwentijt takes pure mathematicians to reason are ideas of mathematical objects, such as triangles and circles. He identifies these bare ideas with the mathematical objects they represent. The bare idea of a triangle is a triangle for

\footnotetext{
26 I adopt Chappell's example here.

27 See also Chappell (1986, p. 187); Patterson (2008, p. 218); Ayers (2000, p. 1067); cf. Nolan (1997, p. 176).

28 See Chappell (1986) for an extensive discussion of the relation between ideas taken objectively and ideas taken materially, and esp. pp. 184-194 for helpful analysis of Descartes's notion of an idea taken objectively.

29 Note that there are two representative relations at work in Descartes. Within the mind, the idea taken materially represents an idea taken objectively (Chappell 1986, pp. 191-192). The idea taken objectively may, in turn, represent an entity external to the mind, which is its formally existing counterpart (Chappell, 1986, pp. 192-193). Cf. Ayers (2000, pp. 1066-1069). See e.g. also Smith (2010, esp. pp. 246-252) for helpful discussion of Descartes's two relations, and for some interpretative issues related to them. Thanks to an anonymous reviewer for critical comments regarding this issue.

30 In what follows, I do not consider whether Nieuwentijt was factually influenced by Descartes, or whether he picked up his somewhat Cartesian vocabulary from other sources. Vermij (1991, pp. 7-12; cf. pp. 42-50) has pointed out that although Nieuwentijt rejects Cartesianism in his mature works, he probably held Cartesian views in his early life (see also Petry 1979, pp. 2-3; Ducheyne 2017a, section 2; b, pp. 275-276). Vermij (1991, p. 152) also points out that Nieuwentijt seems to have possessed some of Descartes's work, but not many other speculative works.
} 
Nieuwentijt. ${ }^{31}$ When Nieuwentijt claims that pure mathematicians study bare ideas, his point is that the entities that pure mathematics studies, mathematical objects, have objective reality. ${ }^{32}$ The ideas that pure mathematics studies are "bare", because pure mathematicians do not verify whether they have formally existing counterparts. As there may not be formally existing triangles, circles etc., mathematical objects are nothing but ideas. ${ }^{33}$

The bare ideas on the basis of which pure mathematicians reason are objectively real mathematical objects, so when pure mathematicians examine and compare bare ideas, they examine and compare mathematical objects, according to Nieuwentijt. Nieuwentijt takes us to have a special type of "experience" (ondervinding) that enables us to determine the properties of our ideas. Nieuwentijt normally uses the term "experience" to refer to effects of existing objects on our bodies or minds (see esp. GC, p. 120). Ordinary experience allows us to determine whether propositions that speak of existing objects are true (e.g. $G C$, p. 130). The special experience we have of our ideas, by contrast, allows us to determine whether propositions that speak of our ideas are true (e.g. GC, pp. 20-21). ${ }^{34}$ Nieuwentijt uses the Cartesian term "clear and distinct understanding" (klaar en distinct begrip) for the experience we have of our ideas (e.g. $G C$, p. 19). According to Nieuwentijt, we know that a proposition that speaks of our ideas is true if we clearly and distinctly understand it to be true (GC, pp. 20-21).

According to Nieuwentijt, pure mathematicians work in the following way. First, they "describe" (beschryven) their bare ideas in definitions. Then they determine the properties of these ideas, and compare them to others $(G C$, p. 11). This leads them to "deduce" (afleiden) propositions: they express by means of language which properties they find in their ideas. If it is immediately clear to everyone that the ideas that a proposition speaks of have the properties the proposition ascribes to them, then the proposition forms an axiom (ibid.). ${ }^{35}$ If this is not immediately clear, the proposi-

\footnotetext{
31 This becomes clear from the fact that Nieuwentijt tends to say that pure mathematics studies bare ideas, rather than the objects of bare ideas (e.g. $G C$, p. 27). He also tends to say that purely mathematical propositions make claims about bare ideas (e.g. $G C$, pp. 21-22). There are some passages in which Nieuwentijt seems to distinguish between bare ideas and their objects (e.g. $G C$, p. 6). I take it that Nieuwentijt regards bare ideas and the objects of bare ideas as one and the same entity. Nieuwentijt does not make this explicit. He does, however, twice mention the mathematician Raphson who, as Nieuwentijt reads him, claims that the objects of pure mathematics are "beings of reason" (Redenwesens) $(G C$, p. 23, cf. p. 3), and who believes that such beings and our ideas of them are "one and the same" (GC, p. 3, cf. pp. 23-24).

32 Ducheyne (2017a, section 2) makes the same observation. Chappell (1997) and Nolan (1997) have argued that Descartes regards mathematical objects as (innate) ideas taken objectively.

33 Note that even on conceptualist readings of Descartes such as those of Chappell (1997) and Nolan (1997), this is not exactly Descartes's view. For Nieuwentijt, the status of a mathematical idea does not fundamentally differ from that of a hippogriff. For Descartes it does. Cf. also Petry (1979, p. 5).

34 Nieuwentijt uses the same word for the two types of experiences on purpose (see $G C$, p. 92). He does emphasize, however, that the two types of experience are quite different (GC, pp. 120-122).

35 As Nieuwentijt himself puts it: "If now that which they [i.e. mathematicians] deduce as a conclusion [tot een besluit afleiden] from these properties (either examined in themselves, or being compared to others), is, to someone who understands the words by means of which they express this [conclusion], immediately clear, and anyone experiences [ondervint] this to take place such and in the same way in his Ideas, then they [i.e. mathematicians] express this in a proposition [voorstel]. Which they therefore call Axiom [Axioma] [...]" $(G C$, p. 11).
} 
tion requires a proof. In a proof, mathematicians "show, how anyone should lead his thoughts, to be able to experience these proposed [voorgestelde] properties of this Idea [...] in his Ideas as well [...]"36 (GC, p. 12). In such a proof, they make use of the definitions, the axioms, and the already demonstrated theorems (ibid.). ${ }^{37}$

Nieuwentijt's characterization of the working method of pure mathematics shows that when we deduce propositions from bare ideas, we do not so much deduce them from other propositions. ${ }^{38}$ Rather, we report the experiences we have of our ideas. The pure mathematician comes to "experience" (i.e. clearly and distinctly understand) whether the objects that a mathematical proposition speaks of have the properties that that proposition assigns to them. If he can make every other person experience this as well, he deduced the proposition from the ideas. Both axioms and theorems count as deduced from bare ideas in this sense. ${ }^{39}$ In the next section, we see that Nieuwentijt's conception of mathematical reasoning helps understand how he can claim that it is possible to deduce false propositions from true ideas.

\section{Deducing propositions from abstracted ideas}

According to Nieuwentijt, reasoning on the basis of the abstracted ideas that mixed mathematicians form of existing objects is exactly the same activity as reasoning on the basis of bare ideas $(G C$, p. 48). Both in pure and in mixed mathematics, to reason on the basis of ideas means: to examine and compare them $(G C, \mathrm{pp} .48,50)$. To understand what it means to mathematically deduce a proposition from abstracted ideas, we therefore need to determine how Nieuwentijt conceives of abstracted ideas.

One straightforward possibility is that Nieuwentijt regards abstracted ideas, just like bare ideas, as mathematical objects that have objective being in our minds. Abstracted ideas could be mathematical objects that represent quantitative features of existing objects. Although Nieuwentijt certainly regards some abstracted ideas as mathematical objects, ${ }^{40}$ this interpretation does not work for Nieuwentijt's general use of the notion of an abstracted idea. First of all, not all abstracted ideas represent quantitative features in Nieuwentijt's eyes. We can for instance form an abstracted idea of the material an object is made of (see $G C$, p. 74). Moreover, the interpretation does not square with Nieuwentijt's characterization of an abstracted idea:

[T] hose [ideas that] show one or more Properties of a Thing (but not, however, all Properties), they [i.e. the philosophers] call Abstractae or subtracted: Therefore, because from the whole Being or from all of the Properties that are in the Thing,

\footnotetext{
36 "tonen $[\ldots]$ hoe yder syne gedagten leiden moet, om de selfde voorgestelde eigenschappen van dit Denkbeelt $[\ldots]$ ook in syne Denkbeelden te kunnen ondervinden [...]".

37 Nieuwentijt's characterization of a mathematical proof is similar to Descartes's. See Hacking (1980) and Nolan (2005) for discussions of Descartes's views on proof.

38 Although Nieuwentijt does suggest that it may be possible to logically deduce all theorems in pure mathematics from the axioms (GC, p. 213).

39 That axioms are deduced from bare ideas according to Nieuwentijt becomes clear from the passage cited in footnote 35 .

40 This becomes clear from GC, p. 49 , cf. p. 25 .
} 
only these are as if Subtracted in thought. Which ones alone one then takes into account, without attending to other Properties of the Thing $(G C$, p. 45$){ }^{41}$

When we form an abstracted idea, we literally "subtract" an object's property and consider it in isolation, according to Nieuwentijt. This suggests that abstracted ideas are what we might call 'objective properties' ${ }^{2}$ : objective counterparts of properties of formally existing objects. This would explain why Nieuwentijt often speaks of "subtracted properties", rather than of subtracted or abstracted ideas (e.g. GC, pp. 63, $65,69,71,74)$. The fact that some of Nieuwentijt's abstracted ideas form mathematical objects does not conflict with this interpretation. An objective triangle could, for instance, be regarded as an objective counterpart of an existing object's shape. The interpretation explains, moreover, how Nieuwentijt can claim that it is possible for abstracted ideas to "roughly coincide" (eenigsints over een te komen) (GC, p. 25) with bare ideas of mathematical objects. Nieuwentijt states, for instance, that the "Subtracted Idea of the orbits of the Planets around the Sun"43 (GC, p. 61) was long thought to be "similarly shaped to that of a Circle"44 (ibid.), whereas it actually "more closely resembled that of an [...] Ellipse [...]"45 (GC, p. 62). Arguably, an objective orbit could resemble an objective ellipse.

Although the proposed interpretation accounts for most of the textual evidence, it does not fully explain Nieuwentijt's use of the notion of an abstracted idea. In Sect. 2, we introduced Nieuwentijt's notion of truth "with respect to" abstracted ideas. We noted that propositions that are deduced from abstracted ideas of existing objects are certainly true with respect to these ideas, according to Nieuwentijt, but possibly false of the existing objects they represent. In our earlier feather-example, the proposition the feather falls to the ground in $4.52 \mathrm{~s}$ would certainly be true with respect to abstracted ideas, in Nieuwentijt's eyes, but probably false of the actual feather. On the interpretation advanced so far, it is difficult to make sense of Nieuwentijt's notion of truth with respect to an abstracted idea. Nieuwentijt suggests that propositions that are true with respect to abstracted ideas are propositions that make true claims about these abstracted ideas (e.g. $G C$, pp. 117, 118, 213). He suggests that a proposition that makes a claim about existing objects can be regarded in two ways. It can be regarded as making a claim about the object, or as making a claim about an abstracted idea of that object. ${ }^{46}$ A proposition that speaks about existing objects is true if these objects "are such, as the Proposition or Conclusion says that they are" 47 (GC, p. 51, cf. p. 117). When we ask whether a proposition that speaks of abstracted or "subtracted" ideas

\footnotetext{
41 "[D]ie [denkbeelden die] een of meer Eigenschappen van een Saak (dog egter niet alle Eigenschappen) vertonen, noemen sy [de Philosophen] Abstractae of afgetrokkene: Daarom om dat van het gehele Wesen of van alle de Eigenschappen die in de Saak syn, dese alleen gelyk als met de gedagten Afgetrokken worden. Welke men dan alleen in aanmerkinge neemt, sonder op andere Eigenschappen van deselve Sake agt te geven".

42 I borrow this term from Chappell (1986, p. 190), who notes that we do not only find objective substances in Descartes, but also objective properties. Cf. Chappell (1997, pp. 120; 122).

43 "het Afgetrokkene Denkbeelt van de wegen der Planeten om de Sonne".

44 "gelykformig aan dat van een Cirkel".

45 "meer overeen quam met dat van een [...] Ellipsis $[\ldots]$ ".

46 This becomes clear, in particular, from $G C$, pp. 118-119.

47 “soodanig syn, als het Voorstel of Besluit segt dat sy syn".
} 
is true, Nieuwentijt says, we ask: "whether these Subtracted Ideas are such in themselves, or have such similarities or differences with other Ideas?"48 (GC, p. 117). It is difficult to see how a proposition that makes a claim about an existing object could also make a claim about an idea that forms an objective property, let alone a true claim.

To make sense of Nieuwentijt's notion of truth with respect to an abstracted idea, it seems that we must assume that he regards these ideas as copies of existing objects themselves. If the proposition the feather falls to the ground in $4.52 \mathrm{~s}$ is to make a claim about an abstracted idea of a feather, for instance, that idea must be a kind of feather. An objective copy of a feather would be a kind of feather. An objective feather cannot have properties in the way a physical feather does, but presumably Nieuwentijt believes that it can have such properties objectively. ${ }^{49}$ It would make some sense, then, to say that an idea that forms an objective copy of a feather has the property falls to the ground in $4.52 \mathrm{~s}$, and that the proposition the feather falls to the ground in $4.52 \mathrm{~s}$ makes a true claim about that idea.

The tension in Nieuwentijt's use of the notion of an abstracted idea can be resolved if we take it to be his view that one and the same abstracted idea can function both as an objective copy of a property of an object, and as an objective copy of that object as a whole. An abstracted idea that forms a copy of a property of a formally existing object could also be regarded as an incomplete copy of the object itself. It can be regarded as an objective counterpart of the formally existing object that is stripped of all but one, or a few, of that object's properties. To give an example: Suppose that we form a perfectly accurate idea of the earth's shape. Considering Nieuwentijt's conception of an idea, this idea would have to be an objective shape that forms a copy of the earth's shape ${ }^{50}$ This shape cannot only be regarded as an objective property, but also as an incomplete objective variant of the earth as a whole. It can be regarded as an objective variant of the earth that is stripped from all of the original earth's properties, except for its shape.

Admittedly, there is not much direct evidence for this reading. However, it seems that we can only make sense of Nieuwentijt's use of the notion of an abstracted idea if we assume that he uses it roughly along these lines. If Nieuwentijt's abstracted ideas can indeed be regarded as incomplete copies of formally existing objects, then this explains why he considers it possible to deduce false propositions from true abstracted ideas. Reasoning in mixed mathematics is the same activity as reasoning in pure mathematics according to Nieuwentijt, we saw. When we deduce a proposition

\footnotetext{
48 "of dese Afgetrokken Denkbeelden sodanig in sig selfs syn, of sodanige oveenkomsten of verschillen hebben met andere Denkbeelden?" Nieuwentijt adds the following clarification to this passage: "that is, whether there can be such consequences [gevolgen] or Conclusions [Besluiten] Mathematically deduced from these Subtracted Ideas, as this Proposition says that can happen?" (GC, p. 117). One could argue, drawing on this remark, that all it means for a proposition to be true with respect to abstracted ideas, according to Nieuwentijt, is that that proposition can be mathematically deduced from these ideas. The abstracted ideas must not have the properties that the proposition ascribes to them. This reading does not square well, however, with the first part of Nieuwentijt's characterization of what it means to be true with respect to an abstracted idea. As becomes clear later, moreover, Nieuwentijt's clarificatory remark is perfectly understandable on the interpretation advanced here.

49 See also Chappell (1986, pp. 188-190) for a discussion of this issue in Descartes.

50 According to Nieuwentijt, an abstracted idea of an object can form an adequate or "complete" (volkomen) idea of one or several of that object's properties $(G C$, p. 45).
} 
from abstracted ideas, we report which properties we "experience" in those ideas. As Nieuwentijt says:

When now the Examining of these Factual [Sakelyke] Ideas as such, and compared with others makes the Examiner, if he pays sufficient attention, experience one Property or another (it may be a similarity, or a difference in these Ideas), [and] when then he expresses that what he experiences by way of Proposing [Voorstellen] (Propositio or Enunciato), he is said to form a Conclusion [een Besluit te maken].

It will be unnecessary to show here more extensively, that the forming of conclusions, in Factual Mathematics happens in the same way from the Factual Ideas, as in the Speculative Mathesis from the bare Ideas $(G C$, p. 50$) .{ }^{51}$

In pure mathematics, a proposition is deducible from bare ideas if it can be established that it makes a true claim about these ideas, according to Nieuwentijt. A proposition is deducible from abstracted ideas if it can be established that it makes a true claim about these abstracted ideas. When we ask whether a proposition is true with respect to abstracted ideas, Nieuwentijt states, we ask "[...] whether there can be such consequences [gevolgen] and Conclusions [Besluiten] Mathematically deduced, as this Proposition says that can happen?"52 (GC, p. 117). In other words: the question whether a proposition can be deduced from abstracted ideas amounts to the question whether that proposition makes a true claim about these ideas. Just as in pure mathematics, this is determined through the "experience" $(G C$, p. 50) we have of these ideas: through clear and distinct understanding ( $G C$, pp. 64, 117, 129).

In Sect. 2, we saw that, according to Nieuwentijt, a proposition that is deduced from an abstracted idea would certainly be true of the formally real object of that idea, if that object would have no properties other than those represented by the abstracted idea. If Nieuwentijt's abstracted ideas form objective copies of formally existing objects that have some, but not all of these objects' properties, then there will be propositions that can be shown to be true of these abstracted ideas, but that may be false of the formally real objects they represent. The proposition the feather falls to the ground in $4.52 \mathrm{~s}$ of our example, for instance, can be shown to be true of an objective variant of the feather that has no properties but its distance to the earth. Considering Nieuwentijt's conception of mathematical reasoning, such propositions count as deducible from the abstracted ideas.

\footnotetext{
51 "Gelyk nu het Beschouwen deser Sakelyke Denkbeelden in sig selfs, en in vergelyking met anderen aan den Beschouwer, als hy behoorlyk op let, de eene of andere Eigenschap (het sy overeenkomst, of verschil in dese Denkbeelden) doet ondervinden, [en] wanneer hy als dan het geen hy aldus ondervint, by manier van Voorstellen (Propositio of Enunciato) uitdrukt, wordt hy gesegt een Besluit te maken.

Het sal onnodig syn hier uitvoeriger aan te toonen, dat het besluiten maken, in de Sakelyke Wiskunde op deselve wyse uit de Sakelyke Denkbeelden geschiet, als in de Speculative Mathesis uit de bloote Denkbeelden".

52 "[...] of "er uit dese Afgetrokkene Denkbeelden sodanige gevolgen en Besluiten Wiskundig kunnen afgeleid worden, als dit Voorstel segt dat kan geschieden?".
} 


\section{Logical reasoning versus reasoning from ideas}

We began this paper with the observation that mathematically deducing propositions from ideas cannot be the same activity as logically deducing propositions from other propositions. A proposition that is mathematically deduced from true abstracted ideas may be false according to Nieuwentijt, whereas a proposition that is logically deduced from true premises must be true. We can now explain how the two types of reasoning differ.

Nieuwentijt's views on logic do not seem fully worked out. Nieuwentijt himself notes that the topic actually does not fall within the scope of his work (GC, p. 204). He only discusses it because he fears that he may have given the impression that "the Mathematicians" (ibid.) even require empirical verification of propositions that are deduced from factually true propositions via.

[...] Arguments [Sluitreden] or Syllogisms, which one finds with the Logicians: of which the Conclusions are always taken to be True, if only the Praemissae or Preceding propositions are Truly and Lawfully stated according to the Rules of Logic (GC, pp. 204-205). ${ }^{53}$

Nieuwentijt seems to adopt his views on logic somewhat blindly from the Port-Royal Logic. ${ }^{54}$ In Logic or the Art of Thinking, Arnauld and Nicole seek to provide a general criterion for determining the validity of syllogisms. According to Arnauld and Nicole, a syllogism is valid if one of the premises "contains" the conclusion, and if the other premise "shows that $[\ldots]$ the containing proposition actually does contain the one we wish to prove" (LAT, III, 10, p. 163). ${ }^{55}$ Arnauld and Nicole distinguish between the intension or "comprehension" of an idea, and its extension. The intension of an idea consists of "the attributes contained in an idea" (LAT, I, 6, p. 39). The extension consists of "the subjects to which the idea applies" (LAT, I, 6, p. 40). Whether a proposition contains another proposition is determined, according to Arnauld and Nicole, by the extensions and the intensions of the terms in these premises. ${ }^{56}$

Nieuwentijt adopts the Port-Royal logicians' characterization of a valid syllogism. For Nieuwentijt, a logical inference is composed of two premises and a conclusion. In a valid inference, the conclusion is deduced from one of the two premises. The other premise serves to help one see that the conclusion can be deduced from the first. ${ }^{57}$ According to Nieuwentijt, a proposition $q$ can be deduced from another proposition $p$ if "nothing is said" (niets gesegt word, GC, p. 206) by $q$ that is not already said by $p$. Put differently, $q$ can be deduced from $p$ if $p$ "comprehends" (begrypt, GC, p. 205) $q$.

It is not clear to what extent Nieuwentijt adopts the Port-Royal logicians' conceptions of intension and extension. Therefore, it is not entirely clear when a proposition

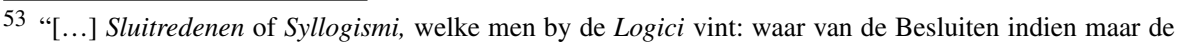
Praemissae of Voorgaande propositien Waar en Wettig na de Regulen der Logica gestelt syn, altyt gehouden worden Waar te syn".

54 He refers to "Ars Cogitandi" (GC, p. 208), which must be a Latin translation of this work.

55 I use $L A T$ as abbreviation for Logic or the Art of Thinking and give references to, respectively, book part, chapter, and page number of the English translation by Buroker (i.e. Arnauld and Nicole 1996).

56 This becomes clear from $L A T$, III, 10, p. 163.

57 This becomes especially clear from GC, p. 208. See also Nieuwentijt's examples at GC, pp. $206-207$.
} 
"comprehends" another proposition according to Nieuwentijt. It does not seem to be Nieuwentijt's view that this is exclusively determined by the meanings or intensions of the terms the propositions contain, or at least not in all cases. According to Nieuwentijt, Peter is mortal is deducible from Peter is human, for instance $(G C$, p. 205). However, he regards the proposition all humans are mortal as an empirical generalization $(G C$, p. 218). ${ }^{58}$ Although Nieuwentijt himself does not speak of extensions, we can say that he implicitly takes terms to have something that we could call an extension: a set of entities to which that term applies. Depending on whether a proposition speaks of existing objects or of ideas, the extensions of its terms consist of existing objects or of ideas. It seems that whether a proposition "comprehends" another proposition depends on the extensions of the terms these propositions contain. ${ }^{59}$ If this is correct, then this explains why, according to Nieuwentijt, a proposition that is logically deduced from true premises must be true as well. We could say that the premises of a logical inference provide information about certain inclusion and exclusion relations between the extensions of the terms they contain. If the premises of a logical inference are true of existing objects, they provide information about relations between sets of existing objects. If this information allows us to determine the truth of another proposition, then this proposition must be true of existing objects as well.

Mathematical reasoning on the basis of ideas differs from logical reasoning on the basis of propositions precisely because what Nieuwentijt describes as logical reasoning does not involve the examination of ideas. Earlier, we saw that when we deduce a proposition from ideas, we consider whether the proposition makes a true claim about these ideas. This type of reasoning does not allow us to determine whether a proposition is true of existing objects. ${ }^{60}$ Whether a proposition can be logically deduced from other propositions, by contrast, is not determined by ideas, but by the logical relations between the propositions. Logical reasoning does allow us to determine whether a proposition is true of existing objects: if the premises of a logical inference are true of existing objects, then so is the conclusion.

Even when we reason logically on the basis of propositions that speak of bare or abstracted ideas, rather than of existing objects, we do something different than when we deduce these propositions from the ideas themselves in Nieuwentijt's eyes, or so it seems. If a proposition is true of ideas, then propositions that are logically deduced from that proposition are certainly true of ideas as well, according to Nieuwentijt. ${ }^{61}$

\footnotetext{
58 It is not clear whether Nieuwentijt believes that terms have meanings or intensions that allow us to determine independently from experience that certain propositions can be deduced from each other. There are some passages that suggest this (see e.g. $G C$, p. 206, example III). If it is Nieuwentijt's view that terms have such intensions, then it seems that these intensions cannot be ideas of the objects that fall under these terms, or at least no abstracted ideas. If B's intension allows us to determine that all $A$ are $C$ can be deduced from all $A$ are B, then B's intension should allow us to determine that $\mathrm{C}$ applies to all of the objects thought under B. However, abstracted ideas of objects do not allow us to determine this.

59 It may be Nieuwentijt's view, however, that in some cases the inclusion and exclusion relations between extensions of terms are determined by their intensions. Cf. the previous footnote.

60 Unless we reason on the basis of adequate ideas. However, Nieuwentijt deems it practically impossible for humans to form adequate ideas of existing objects (GC, pp. 46-47). See also Ducheyne (2007, pp. 704-705; 2017a, section 2; b, p. 290).

61 Nieuwentijt does not make this fully explicit. Before starting his discussion of logical deduction, he notes that he will not say much about logical inferences regarding "the Ideal" (het Denkbeeldige), because
} 
When we deduce a mathematical proposition like all equilateral triangles have angles that equal two straight angles from ideas, we determine its truth value through the experience we have of these ideas: through clear and distinct understanding. When we logically deduce this proposition from other propositions, such as from all triangles have angles that equal two straight angles, no clear and distinct understanding appears to be involved. ${ }^{62}$ The same distinction can be made for abstracted ideas.

Because logical reasoning does not involve the examination of ideas, there is another important difference between the two types of reasoning. Mathematical reasoning on the basis of ideas allows us to determine whether propositions that make claims about ideas are true without relying on other propositions, according to Nieuwentijt. Logical reasoning does not. We can determine that a proposition that speaks of ideas is true by deducing it from other propositions, Nieuwentijt states, but at some point we must reach premises whose truth is established without the use of further propositions. For this reason, pure mathematicians need axioms, he states. Axioms

[...] are taken to be True because of a Clear and distinct understanding or because of these Experiences in the Ideas alone; and argued by no Inference [uit geen gevolg]: but by themselves: that is, by this Experience in the understanding ( $G C$, p. 213). ${ }^{63}$

Nieuwentijt makes the same point for propositions that make claims about abstracted ideas. We can establish that a proposition like the feather falls to the ground in $4.52 \mathrm{~s}$ from our earlier example is true of abstracted ideas by logically deducing it from other propositions that are true of abstracted ideas. However, eventually we must reach premises whose truth we establish through "[...] the Experiences, which one experiences in these Subtracted Ideas [...]"64 (ibid.), Nieuwentijt states. In other words, at some point we must reach premises that are not deduced from propositions about abstracted ideas, but from the abstracted ideas themselves. ${ }^{65}$ Nieuwentijt suggests that it may be possible to logically deduce all purely mathematical theorems from the axioms (ibid). However, as at least the truth of the axioms cannot be established by logical reasoning, logical reasoning alone does not allow us to establish truths about bare ideas. The same holds for abstracted ideas.

\section{Conclusion}

Nieuwentijt does not regard logic as a part of mathematics or vice versa, like Ducheyne and Petry suggest, and Beth's suggestion that Nieuwentijt's position is akin to logicism

\footnotetext{
Footnote 61 continued

he thinks that his reader will be able to infer this from his discussion of "the Factual" (het Sakelyke) (GC, p. 205). That this is what we should take to be Nieuwentijt's point is suggested by GC, pp. 213-214.

62 Nieuwentijt indicates nowhere in his chapter on logic that clear and distinct understanding plays any role when we logically deduce propositions from other propositions.

63 " [...] om een Klaar en distinct begrip of om dese Ondervindinge in de Denkbeelden alleen voor Waar aangenomen; en uit geen Gevolg betoogt worden: maar door sig selfs: dat is, door dese Ondervinding in het verstant".

64 "[...] de Ondervindinge, welke men in dese Afgetrokkken Denkbeelden ondervint [...]".

65 Thanks to an anonymous reviewer for pressing this issue.
} 
is misleading. ${ }^{66}$ Although Nieuwentijt does not himself speak of such things as logical truths, his views on logic commit him to the existence of such truths. Propositions of the form all $A$ 's are $B$ and all $B$ 's are $C$, so all $A$ 's are $C$, for instance, should be true in virtue of logic alone for Nieuwentijt. Such logical truths have a different status than mathematical truths.

In Nieuwentijt, we implicitly find a distinction that Macbeth (2017) has recently ascribed to Descartes, namely a distinction between logically and non-logically necessary truths. According to Macbeth, Descartes's creation doctrine, his claim that necessary truths are created by God, applies only to non-logically necessary truths. The negations of logical truths "are absolutely impossible", Macbeth (2017, p. 19) claims. Even God could not have made them true. For this reason, logical truths did not need to be created. Non-logically necessary truths such as mathematical truths have to be created according to Descartes, precisely because they do not form logical truths, Macbeth argues. Non-logically necessary truths are true in virtue of rules that God created, and that could have been created otherwise (Macbeth 2017, esp. pp. 19-22). ${ }^{67}$

Because the truth of mathematical propositions does not depend on the factual situation in the world according to Nieuwentijt, we can say that he regards mathematical truths as necessary truths. However, mathematical truths do rely on the properties of our ideas for Nieuwentijt: if our ideas would be different, there would be different mathematical truths, it seems. ${ }^{68}$ Mathematical truth has much in common with empirical truth for Nieuwentijt. True empirical propositions express facts about the world, true mathematical propositions express facts about ideas.

Logical truth differs from mathematical truth in Nieuwentijt's system, because it does not rely on our ideas. Nieuwentijt's discussion of logic shows that he presupposes that there are specific logical relations between propositions, which make logical deduction possible. To put it in Wittgensteinian terms: Nieuwentijt assumes that the world has a certain "logical structure" $(T L P, 4.014) .{ }^{69}$ Logical truths are true in virtue

\footnotetext{
66 Of course, both pure and mixed mathematicians can make use of logical inferences, and Nieuwentijt points out at various places that they do (e.g. GC, pp. 106-114).

67 Funkenstein (1975) argues that there is a distinction between logically and non-logically necessary truths in Descartes as well, but on different grounds.

68 There only seem to be mathematical truths about ideas that we actually have, and not, for instance, about ideas that we could have in Nieuwentijt's eyes (I thank an anonymous reviewer for raising this issue). Nieuwentijt does not seem to make room in his ontology for such things as non-actual ideas. This means that different collections of mathematical truths can be true, depending on which ideas we happen to have formed. Moreover, although Nieuwentijt is probably unaware of this, it appears to be possible within his philosophy to have mathematical propositions that are true according to one system of ideas, but false according to another. Nieuwentijt states that pure mathematics should not accept any propositions as true that contradict already demonstrated propositions (GC, p. 344). However, it seems that if pure mathematicians would have started out with different ideas, they might have demonstrated a collection of truths that conflicts with the set of truths we happen to have demonstrated. There would also be room in Nieuwentijt's system, it seems, to dispute the truth of e.g. the parallel postulate on the ground that we do not clearly and distinctly understand it to be true (cf. Petry 1979, p. 5, who makes a related point).

It seems to be Macbeth's (2017) view that non-logically necessary truths are true in virtue of ideas according to Descartes as well (see pp. 19-21), but in a slightly different way than they are for Nieuwentijt. 69 In referring to Wittgenstein, I refer to the proposition numbers of the Tractatus Logico-Philosophicus, abbreviated as TLP, and use the Ogden translation (i.e. Wittgenstein 1981).
} 
of this logical structure alone. As we do not rely on ideas in logical deduction according to Nieuwentijt, logical truth does not rely on ideas in his system either. A proposition that expresses a logical truth would not, like a true mathematical proposition, express a fact about our ideas for Nieuwentijt. It would merely "show" (cf. TLP, 6.22; cf. 6.124) the logical structure Nieuwentijt presupposes. As Macbeth describes what she takes to be Descartes's position: logical truths "have no content" $\left(2017\right.$, p. 19) ${ }^{70}$ The fact that Nieuwentijt does not himself recognize that logical truths form a different category of truths within his system reflects this.

Acknowledgements The research for this paper was conducted as part of the research project 'Antimathematicism in philosophy', which is supported by the Research Foundation-Flanders (FWO) under Grant G061215N. The paper initially arose from a series of discussions with Jonathan Shaheen, who greatly helped me develop my ideas and provided excellent feedback on a number of drafts that led to this paper. I thank him for this. I am also very grateful to Eric Schliesser and Maarten van Dyck, with whom I had valuable conversations on the issues discussed in the paper, and who provided important and insightful comments on earlier versions. I thank them for their great help as well. Drafts of this paper were presented at Ghent University, at the University of Amsterdam, at the fourth Dutch Seminar in Early Modern Philosophy in Groningen, at the Ninth French Philosophy of Mathematics Workshop in Nancy, and at HOPOS 2018. I thank the audiences for helpful discussions and comments. I owe special thanks to Danielle Macbeth for drawing my attention to her article after the conference in Nancy. Thanks also to Ruth Boeker for pointing me in a similar direction. Lastly, I warmly thank two anonymous reviewers for their helpful and constructive comments and questions.

Open Access This article is distributed under the terms of the Creative Commons Attribution 4.0 International License (http://creativecommons.org/licenses/by/4.0/), which permits unrestricted use, distribution, and reproduction in any medium, provided you give appropriate credit to the original author(s) and the source, provide a link to the Creative Commons license, and indicate if changes were made.

\section{References}

Arnauld, A., \& Nicole, P. (1996). Logic or the art of thinking (J. V. Buroker, Trans.). Cambridge: Cambridge University Press.

Ayers, M. (2000). Ideas and objective being. In D. Garber \& M. Ayers (Eds.), The Cambridge history of seventeenth-century philosophy (pp. 1062-1107). Cambridge: Cambridge University Press.

Beth, E. W. (1954). Nieuwentyt's significance for the philosophy of science. Synthese, 9(6), 447-453.

Cartwright, N. (1983). How the laws of physics lie. Oxford: Clarendon Press.

Chappell, V. (1986). The theory of ideas. In A. O. Rorty (Ed.), Essays on Descartes' Meditations (pp. 177-198). Berkeley: University of California Press.

Chappell, V. (1997). Descartes's ontology. Topoi, 16, 111-127.

Descartes, R. (1964-1976). Oevres de Descartes. In C. Adam \& P. Tannery (Eds.) (12 vols.). Paris: Vrin/C.N.R.S.

Descartes, R. (1984). The philosophical writings of Descartes (J. Cottingham, R. Stoothoff, \& D. Murdoch, Trans.) (Vol. II). Cambridge: Cambridge University Press.

Ducheyne, S. (2007). 'Ignorance is bliss': On Bernard Nieuwentijt's doctrina ignorantia and his insight in scientific idealization. Rivista di Storia della Filosofia, 62(4), 699-710.

\footnotetext{
70 The comparison between Wittgenstein and Nieuwentijt came to my mind after reading Macbeth's paper. I have some objections against the exact way in which Macbeth works out her interpretation of Descartes. I am not fully convinced, for instance, that Descartes consciously distinguished between logically and nonlogically necessary truths in the way Macbeth suggests. Nieuwentijt's case shows that it may be possible to defend Macbeth's thesis without assuming this. It may suffice to show that Descartes is committed to the distinction. I do think that Macbeth is correct that Descartes's distinction between synthetic and analytic types of demonstration is important in this respect (see Macbeth 2017, pp. 22-24).
} 
Ducheyne, S. (2017a). Constraining (mathematical) imagination by experience: Nieuwentijt and van Musschenbroek on the abuses of mathematics. Synthese. https://doi.org/10.1007/s11229-017-1392-1.

Ducheyne, S. (2017b). Curing pansophia through eruditum nescire: Bernard Nieuwentijt's (1654-1718) epistemology of modesty. HOPOS, 7, 272-301.

Funkenstein, A. (1975). Descartes, eternal truths, and the divine omnipotence. Studies in History and Philosophy of Science, 6(3), 185-199.

Hacking, I. (1980). Proof and eternal truths: Descartes and Leibniz. In S. Gaukroger (Ed.), Descartes. Philosophy, mathematics and physics (pp. 169-180). Sussex: Harvester Press.

Macbeth, D. (2017). Descartes on the creation of the eternal truths. Acta Baltica Historiae et Philosophiae Scientiarum, 5(1), 5-27.

Nieuwentijt, B. (1720). Gronden van zekerheid, of de regte betoogwyze der wiskundigen so in het denkbeeldige, als in het zakelyke: ter wederlegging van Spinosaas denkbeeldig samenstel; en ter aanleiding van eene sekere sakelyke wysbegeerte. Amsterdam: Joannes Pauli.

Nolan, L. (1997). The ontological status of Cartesian natures. Pacific Philosophical Quarterly, 78, $169-194$.

Nolan, L. (2005). The ontological argument as an exercise in Cartesian therapy. Canadian Journal of Philosophy, 35(4), 521-562.

Patterson, S. (2008). Clear and distinct perception. In J. Broughton \& J. Carriero (Eds.), A companion to Descartes (pp. 216-234). Malden, MA: Blackwell.

Petry, M. J. (1979). Nieuwentijt's criticism of Spinoza. Mededelingen vanwege het Spinozahuis 40. Leiden: Brill.

Smith, K. (2010). Matter matters. Metaphysics and methodology in the early modern period. Oxford: Oxford University Press.

Vermij, R. H. (1989). Bernard Nieuwentijt and the Leibnizian calculus. Studia Leibnitiana, 21(1), 69-86.

Vermij, R. H. (1991). Secularisering en natuurwetenschap in de zeventiende en achttiende eeuw: Bernard Nieuwentijt. Amsterdam: Ropodi.

Wittgenstein, L. (1981). Tractatus logico-philosophicus (C. K. Ogden, Trans.). London: Routledge. 